\title{
Sulphur deposit account
}

\author{
R. A. Barnes looks at an OECD study on \\ the transport of air pollutants over long distances
}

\begin{abstract}
THE Final Report of the Organisation for Economic Cooperation and Development (OECD) study on the long range transport of air pollutants within north-west Europe was derestricted last week. It has its origins in the first European network of sites to monitor the chemical composition of precipitation which was established in Scandinavia in 1947. In the 1950s this was extended to other countries and became known as the European Air Chemistry Network. A first detailed analysis of the data, performed by Odén in 1968, showed that an area of highly acid precipitation ( $\mathrm{pH} 3-4$ ) located in the industrial heart of Europe was expanding from year to year. This finding was paralleled by the observation that rivers and lakes in southern Scandinavia were also becoming more acidic and so it was decided that a more detailed study of the origins of the acidity was required.
\end{abstract}

The Scandinavians in particular have expressed great concern that the increasing acidification of inland waters was causing the observed fall in fish populations and was also reducing forestry production. In their opinion, the sources of acid precipitation were sulphur dioxide emissions from the heavily industrialised countries of north-west Europe, particularly those from the UK. This latter view was based on the assumption that southwest winds prevailed and that the UK policy of making major industrial emissions from tall chimneys (the 'tallstack' policy) to reduce nearby surface concentration-which affects about half the total UK emission-is particularly effective in encouraging the transport of pollutants over long distances.

The OECD programme began in 1972 with the aim of determining the relative importance of local and distant sources of sulphur compounds within European countries, special attention being paid to the question of precipitation acidity. Initially ten countries agreed to participate actively-Austria, Denmark, the Federal Republic of Germany, Finland, France, the Netherlands, Norway, Sweden, Switzerland and the United Kingdom-and in 1974 Belgium also joined. Although several surveys have already been made of air pollution fluxes and depositions within certain parts of Europe, the OECD

R. A. Barnes is at the Central Unit on Environ R. A. Barnes is at the Central Unit on Environ-
mental Pollution in the UK Department of the Environment study is the first comprehensive investigation of air pollution movement on a continental scale. Data analysis and interpretation, together with preparation of the final report, has been the responsibilty of the Norwegian Institute for Air Research.

The research programme consisted of observations based primarily on a network of sampling stations, and predictive modelling. In all, 76 ground level sites, sampling on a daily basis, were in operation at one time or another- 8 in the UK and 23 in Norway. They were located, with moderate success, to represent rural conditions within a geographic region. Mean sulphur dioxide and sulphate aerosol concentrations observed at these sites ranged from about $20 \mu \mathrm{g} \mathrm{m}^{-3}$ and $10 \mu \mathrm{g} \mathrm{m}^{-3}$ respectively, close to the major source regions, to about $2 \mu \mathrm{g} \mathrm{m}^{-3}$ and $0.5 \mu \mathrm{g} \mathrm{m}^{-3}$ respectively in the remote areas of northern and western Europe. The higher of the sulphur dioxide figures would be approximately a factor of 5 less than in the source areas themselves, whereas the longer lived and slowly formed sulphate species would be more or less the same. The sulphate in precipitation data show a similar geographical distribution to the air concentrations, with values ranging from 5 to less than $1 \mathrm{mg} \mathrm{l}^{-1}$. In some areas (for example south-west Scandinavia and Switzerland), however, where locally increased precipitation produces greater deposition than in surrounding districts, the pattern is modified. Strong acid in precipitation shows a distribution similar to that of sulphate but with notable differences in some areas. It seems to be due to both sulphuric and nitric acids in proportions of between $3: 1$ and $1: 1$

\section{Sector analysis}

A sector analysis was performed on the surface measurements. Using 850 mbar $(1,200-1,500 \mathrm{~m}$ altitude) trajectories they were allocated to six directional arcs and a mean value was calculated. The results show that high mean concentrations and/or depositions were not randomly oriented, but were directed towards the main areas of emission. When these emitting areas lie to the west of the receptor, concentrations are relatively low but aggregate depositions high. The low concentrations are probably a consequence of the higher wind speed and fewer stagnant, stable, conditions in westerly regimes, while the higher depositions would be related to the greater frequency of precipitation. In most parts of western Europe, higher concentrations are usually found in sectors directed towards the south and south-east, although these do not necessarily result in particularly high annual deposition totals. Winds from such directions are generally associated with a higher frequency of stagnant and stable conditions over source areas which would lead to the high concentrations, and with limited convective or frontal rainfall, wet deposition would tend to be limited. In south-west Norway, however, orographic precipitation in southerly and south-easterly winds, coupled with high sulphate concentrations, produces annual depositions in these sections comparable to those experienced in the westerly winds where precipitation is more frequent and plentiful.

Unfortunately, the sector analysis does not, in general, give a clear indication of which sources give rise to what fraction of the concentrations in a given sector. Because of its geographic position and relative isolation, however, an estimate can be made of the mean contribution of emissions in the British Isles to deposition in Norway and the Netherlands. In addition to the average $0.8 \mathrm{mg} \mathrm{SO}_{4} \mathrm{~L}^{-1}$ and $25 \mu \mathrm{Eq} \mathrm{l}^{-1}$ strong acid background in rainfall from Atlantic air, to which sources in North America seem to contribute, emissions in the UK and Ireland give rise to $1.0 \mathrm{mg} \mathrm{SO} \mathrm{S}^{-1}$ and $20 \mu \mathrm{Eq} \mathrm{I}^{-1}$ strong acid. Mean concentrations at Norwegian sites due to other emission areas range up to $8.7 \mathrm{mg} \mathrm{SO}_{4} 1^{-1}$ and $140 \mu \mathrm{Eq}^{-1}$ strong acid.

Several of the participating countries used instrumented aircraft to obtain data on above-surface concentrations of air pollutants. Flights were usually made under specific meteorological conditions and never at night or in cloud. The results confirm that under these conditions, sulphur compounds are normally transported in the lowest $2 \mathrm{~km}$ of the atmosphere, generally with a peak concentration a few hundred metres above ground level and a progressive decline above that height. The average mixing height under flight conditions was found to be 1,200$1,300 \mathrm{~m}$, although individual vertical profiles varied considerably. The flights also showed that under certain conditions distinct plumes of pollutants existed several hundred kilometres downwind of major source areas.

Reference has frequently been made to 'episodes', when substantial amounts of wet sulphate deposition occur over a period of less than a day, without any attempt at a formal definition. 
Since such occasions, on which a substantial amount of the total annual wet deposition at a site may occur on one day, are likely to be of particular ecological significance, a working definition has been formulated: episode-days at a site are those with the highest wet depositions which, when summed, make up $30 \%$ of the annual total. An area is 'highly episodic' if $30 \%$ of its total annual wet deposition occurs on less than $10 \%$ of wet days. By these definitions parts of Norway, Finland, Sweden, Switzerland and Scotland are highly episodic with respect to sulphate. Sulphate episodicity has been shown to be relatively independent of precipitation episodicity.

Mathematical modelling was employed to obtain a more complete pattern of concentration and deposition in Europe. Estimates were made for 1974 only, and are unlikely to be the same for other years, especially in the case of wet deposition. One of the primary inputs to the models was detailed sulphur dioxide emission figures for the whole of Europe. For the 11 participating countries, man-made emissions were estimated to be 9 million tonnes as sulphur in 1973. Emissions of sulphur from other European countries were calculated to be $16 \mathrm{Mt}$ in 1973 from much less reliable data. The total emission of approximately $25 \mathrm{Mt}$ is approximately twice that in 1950, although some countries have contributed to the increase much less than others (the UK rise between 1950 and 1973 , for example, was about $30 \%$ ). Natural emissions were calculated to represent less than $10 \%$ of the man-made onies over the continent as a whole.

For use in the models, the national sulphur dioxide emission totals were allocated to a $127 \times 127 \mathrm{~km}$ grid, using population and industrial statistics and simple seasonal adjustments made to arrive at emission figures representative

Estimated budget for dry plus wet deposition of sulphur for 1974 (Unit: $-10^{3}$ tonnes of sulphur) ${ }^{1}$

\begin{tabular}{lrc}
\hline Countries & $\begin{array}{c}\text { Sulphur } \\
\text { received }\end{array}$ & $\begin{array}{c}\text { Sulphur } \\
\text { emitted }\end{array}$ \\
Austria & 300 & 221 \\
Belgium & 200 & 499 \\
Denmark & 100 & 312 \\
Federal Republic & & \\
$\quad$ of Germany & 1,250 & 1,964 \\
Finland & 400 & 274 \\
France & 1,000 & 1,616 \\
The Netherlands & 150 & 391 \\
Norway & 250 & 91 \\
Sweden & 500 & 415 \\
Switzerland & 100 & 76 \\
United Kingdom & 1,000 & $2,883^{2}$ \\
Czechoslovakia, German & & \\
$\quad$ Democratic Republic, & & \\
Italy, Poland and & & \\
$\quad$ other areas & 11,000 & - \\
\hline
\end{tabular}

1 Numbers are rounded to one significant figure and accurate to within about $\pm 50 \%$
Includes $80 \times 10^{3}$ tonnes of sulphur from Ireland. of individual days. As a first aproximation $25 \%$ of the emission in any grid element was assumed to be deposited in that element.

\section{Two models}

A Lagrangian model was used to estimate the long range transport of sulphur on a continental scale and the so-called 'Trajectory Model' was employed to estimate the effect of any one country's emissions on the concentrations and depositions in any other country. Both functioned by considering emissions and depositions in individual grid squares and air movements according to $850 \mathrm{mbar}(1,200-1,500 \mathrm{~m})$ trajectories. Unfortunately, the choice of a coarse grid (which was necessitated by the low precision of emission data and trajectories, together with limited computing facilities) has caused the very steep gradients of sulphur concentration which exist in reality to be smoothed across $127 \mathrm{~km}^{2}$. The models therefore only give a very general picture of concentration and deposition with a considerable degree of uncertainty on the accuracy of predicted values at any given point. The relatively coarse grid also made it difficult for one of the main objectives of the programme-the effect of local sources on concentrations and depositions--to be achieved.

The model estimates of daily mean sulphur dioxide and sulphate aerosol concentrations do not agree very well with observed data, correlation coefficients ranging from insignificant values to 0.6 and 0.4 to 0.8 , respectively. The poorer correlation in the case of the shorter lived species (sulphur dioxide) reflects the greater effect of grid smoothing in this case. The correspondence between observed and calculated annual mean concentrations, however, at about 0.9 in both cases, is much better.

As would be expected, the estimated dry deposition pattern for sulphur in Europe strongly reflects the emission field with a maximum of $10 \mathrm{~g} \mathrm{~m}^{-2} \mathrm{y}^{-1}$ in the major source areas and a minimum of about $0.1 \mathrm{~g} \mathrm{~m}^{-2} \mathrm{y}^{-1}$ in remote regions. There is a high degree of qualitative agreement and quantitative similarity between the sulphur wet deposition fields estimated by each of the two models, and that prepared from observed data. To a certain extent, this agreement was to be expected, since all three approaches employ the same grid-smoothed precipitation map. The technique used for preparing the grid assumes zero precipitation more than $100 \mathrm{~km}$ from the nearest observation over land and $300 \mathrm{~km}$ over the sea. Thus, for grid elements in the centre of the North Sea, the precipitation is reckoned to be about $10 \%$ of that in eastern and central England. On a fairly arbitrary basis, it has been estimated that, for this reason, the contribution of British emission to sulphur wet deposition in southern Scandinavia has been overestimated by about $20 \%$.

A regression of observed mean sulphate concentrations in precipitation against weighted mean values of calculated aerosol sulphate concentration, used by the Trajectory Model to estimate sulphur wet deposition due to one country in any other country, has shown that a good relationship $(r=0.9)$ exists for Norwegian and Finnish data. The results suggest a natural background sulphate concentration of $0.8 \mathrm{mg} \mathrm{l}^{-1}$ in precipitation, a figure confirmed by the sector analysis. This regression has been used in the budget calculations for these two countries. A similar regression on data from the remaining countries, however, shows a much wider scatter $(r=0.36)$ and an implied background of $2.0 \mathrm{mg}^{-1}$. These results are probably a reflection of the influence of local sources in countries other than Norway and Finland, and would result in a great deal of the wet deposition in a given country being unattributed to any particular source. As a compromise, a relationship using all available data $(r=0.73)$ and a background' of $1.2 \mathrm{mg} \mathrm{l}^{-1}$ is employed for all countries except Norway and Finland.

For several reasons, therefore, the Trajectory Model has not proved capable of estimating the dry or wet deposition in any one country due to emission in any other country to an accuracy greater than $\pm 40 \%$. Thus, the corresponding total (dry + wet) deposition figures are not accurate to more than $\pm 50 \%$. However, the estimates of the Trajectory Model do give a useful indication of the extent and magnitude of transboundary transport of sulphur compounds. Both models indicate that, within the area as a whole, about $50 \%$ of the sulphur emitted is dry deposited and $30 \%$ wet deposited. The balance leaves the region.

The OECD study has provided a first comprehensive insight into the long distance transport of air pollutants on a continental scale. It is far from definitive, but it has confirmed that sulphur compounds travel long distances in the atmosphere over Europe, and that the air quality in any one country is measurably affected, in a very complex fashion, by emissions in another. Much more precise and detailed work is required if the phenomenon is to be fully quantified, the report itself listing a number of facets which require further investigation. These could be taken into account by an Economic Commission for Europe study, at present in a planning stage. 